\title{
The Brown Anole, Anolis sagrei Duméril and Bibron 1837 (Dactyloidae), State Record and Introduction Pathway
}

\author{
Michael C. Granatosky ${ }^{1}$, and Kenneth L. Krysko ${ }^{2}$
}

\begin{abstract}
${ }^{1}$ Department of Evolutionary Anthropology, Duke University, Durham, North Carolina 27708, USA (michael.granatosky@duke.edu) ${ }^{2}$ Division of Herpetology, Florida Museum of Natural History, University of Florida, Gainesville, Florida 32611, USA (kenneyk@ufl.edu)
\end{abstract}

$\mathrm{T}$ he Brown Anole, Anolis sagrei (Duméril and Bibron, 1837), is indigenous to Cuba and The Bahamas, and is well known for its invasive capabilities and tendency to compete with native species (i.e., the Green Anole, $A$. carolinensis in Florida; Gerber 1991, Echternacht 1999, Campbell 2000; Fig. 1). The first record of this species in Florida was reported in 1887 (Garman 1887), and it has established itself steadily throughout the state, with additional U.S. introductions in Alabama, Arkansas, Georgia, Hawaii, Louisiana, Ohio, South Carolina, South Dakota, Tennessee, Texas, and Virginia (Campbell 1996, Lever 2003, Kraus 2009, Krysko and Granatosky 2010, Meshaka 2011). The spread of the species appears to rely largely on anthropogenic influences via transport by motor vehicles or with potted landscaping vegetation (Godley et al. 1981, Campbell 1996, 2003). Herein, we report three $A$. sagrei from a single location in Durham, North Carolina. These represent the first records of $A$. sagrei in the state of North Carolina (Kraus 2009), and likely represents a recent and isolated introduction event.

On 18 July 2013, MCG collected a neonatal Anolis sagrei (UF-Herpetology 170713) and a hatched eggshell (UF-Herpetology 170714) from the Garden Center of Lowe's Home Improvement, 117 William Penn Plaza, Durham, Durham County, North Carolina (36.044171, -78.900326, Datum WGS84, 122 m elevation). Both specimens were collected from an ornamental Mandevilla plant (Mandevilla sp.) that originated from Costa Farms, 22290 SW 162nd Avenue, Miami, Miami-Dade County, Florida (25.559413, -80.453794, Datum WGS84, 3 m elevation). A second neonate was observed, but escaped capture. On 19 July 2013, MCG returned to the same location and collected two additional neonates (UF-Herpetology 170715-170716). No additional $A$. sagrei were observed. All of these neonatal lizards were $<20 \mathrm{~mm}$ SVL, and deposited in the Division of Herpetology at the Florida Museum of Natural History. Max A. Nickerson confirmed the identity of the specimens and Fred Kraus (pers. comm.) confirmed that these were state records and that he was unaware of any other publications documenting the species in North Carolina.

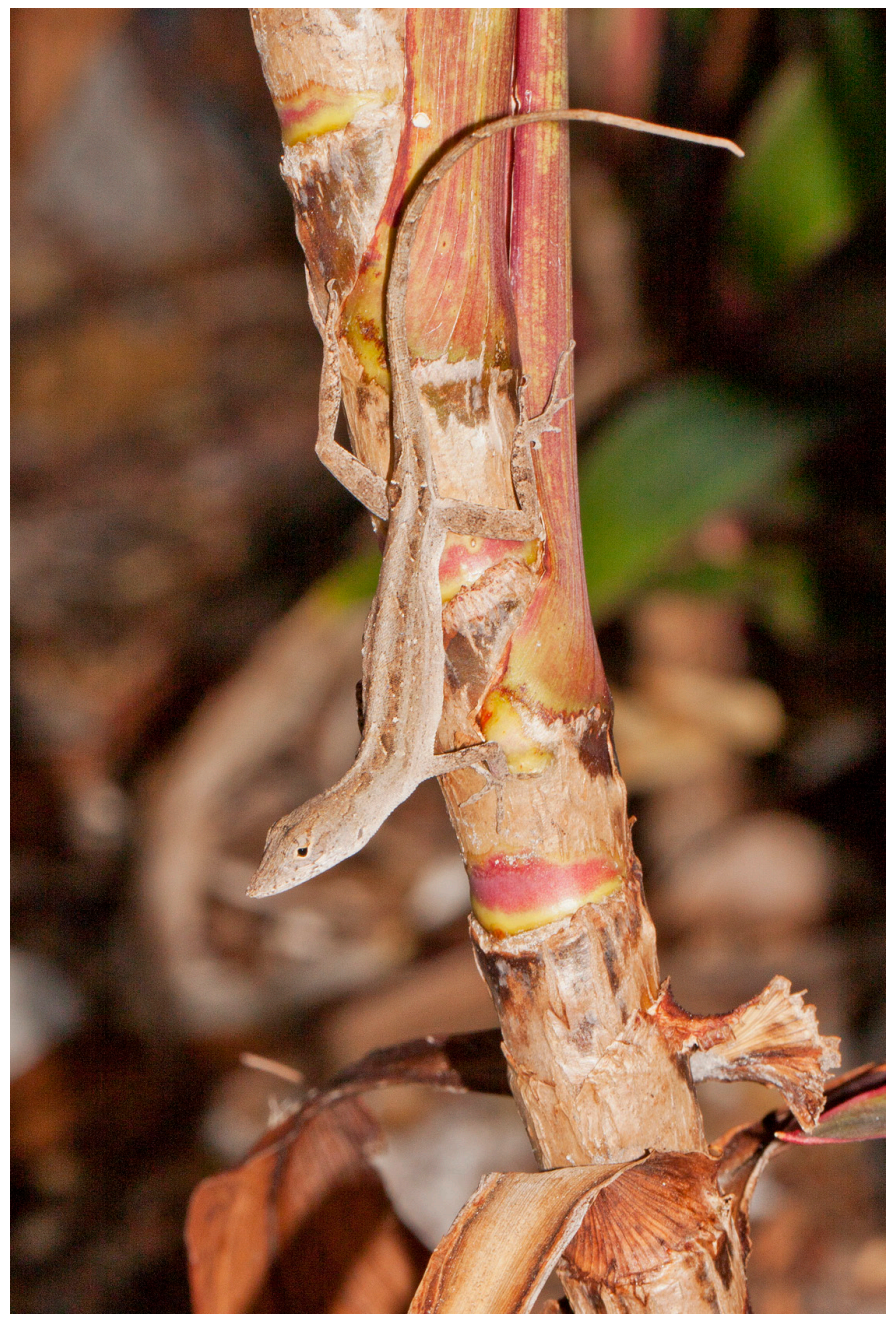

Fig. 1. Representative juvenile Brown Anole, Anolis sagrei (UF-Herpetology 168547), from Ramrod Key, Monroe County, Florida. Photograph by Kenneth L. Krysko. 
Because only neonates were observed at the collection site, we believe that our observation represents a single introduction event. All individuals were encountered on a single species of ornamental plant that originated from a locality where A. sagrei is abundant. This suggests that the introduction into North Carolina occurred via the transport of potted landscaping vegetation. The introduction of nonnative amphibians and reptiles by means of cargo or ornamental plant transfer represents, at least in Florida, a recognized introduction pathway second only to the pet trade (Krysko et al. 2011). Further effort should be undertaken by ornamental plant export facilities to assure that their products are free from pest species.

\section{Acknowledgments}

We thank Fred Kraus for information on our new state record; Max A. Nickerson for confirming species identification of specimens; and Gad Perry, Robert Powell, and an anonymous reviewer for helpful comments on this paper.

\section{Literature Cited}

Campbell, T.S. 1996. Northern range expansion of the Brown Anole (Anolis sagrei) in Florida and Georgia. Herpetological Review 27:155-157.

Campbell, T.S. 2000. Analysis of the effects of an exotic lizard (Anolis sagret) on a native lizard (Anolis carolinensis) in Florida, using islands as experimental units. Ph.D. Dissertation, University of Tennessee, Knoxville.

Campbell, T.S. 2003. The introduced Brown Anole (Anolis sagrei) occurs in every county in peninsular Florida. Herpetological Review 34:173-174.

Echternacht, A.C. 1999. Possible causes for the rapid decline in population density of Green Anoles, Anolis carolinensis (Sauria: Polychrotidae) following invasion by the Brown Anole, Anolis sagrei, in the southeastern United States. Anolis Newsletter V:22-27.

Garman, S. 1887. On West Indian Iguanidae and on West Indian Scincidae in the collection of the Museum of Comparative Zoology at Cambridge, Mass., U.S.A. Bulletin of the Essex Institute 19:25-50.

Gerber, G.P. 1991. Anolis sagrei and Anolis carolinensis in Florida: Evidence for interspecific predation. Anolis Newsletter IV:49-53.

Godley, J.S., F.E. Lohrer, J.N. Layne, and J. Rossi. 1981. Distributional status of an introduced lizard in Florida: Anolis sagrei. Herpetological Review 12:84-86.

Kraus, F. 2009. Alien Reptiles and Amphibians, a Scientific Compendium, and Analysis. Invading Nature: Springer Series in Invasion Biology 4. Springer, Dordrecht, The Netherlands.

Krysko, K.L. and M.C. Granatosky. 2010. Anolis sagrei (Brown Anole). Geographic Distribution. Herpetological Review 41:511.

Krysko, K.L., J.P. Burgess, M.R. Rochford, C.R. Gillette, D. Cueva, K.M. Enge, L.A. Somma, J.L. Stabile, D.C. Smith, J.A. Wasilewski, G.N. Kieckhefer III, M.C. Granatosky, and S.V. Nielsen. 2011. Verified non-indigenous amphibians and reptiles in Florida from 1863 through 2010: Outlining the invasion process and identifying invasion pathways and stages. Zootaxa 3028:1-64.

Lever, C. 2003. Naturalized Reptiles and Amphibians of the World. Oxford University Press, Oxford.

Meshaka, W.E., Jr. 2011. A runaway train in the making: Exotic amphibians, reptiles, turtles, and crocodilians of Florida. Monograph 1. Herpetological Conservation and Biology 6:1-101. 